\title{
Integral curses of the disc drama model with fundamental dynamic characteristics tt-ds
}

\author{
E Niculae ${ }^{1}$, A Dimitrescu ${ }^{1}$, C Babiş ${ }^{2}$, O Chivu ${ }^{2}$ and L Dascălu ${ }^{2}$ \\ ${ }^{1}$ Theory of Mechanisms and Robots Department, Politehnica University, Bucureşti, România \\ ${ }^{2}$ Materials Technology and Welding Department, Politehnica University, București, România \\ banicaelisabeta29@yahoo.com
}

\begin{abstract}
The paper deals with the dynamic response of mechanisms with standardized inertial and mechanical characteristics. Moment or inertial mass is periodically variable with displacement, and torque or mechanical force are periodically variable with displacement and represented by linear, square or cubic functions in relation to speed. In this paper both the inertial moment and the torque variation were used for the T-shift. For the variations of torque torque versus speed, the straight-inclined DS was used. Comparable results charts are based on computer programs.
\end{abstract}

Keywords: disc drama model, dynamic characteristics, $t$ t-ds.

\section{Introduction}

The movement of machines and mechanisms with a single degree of mobility can be studied on dynamic models, rotating discs, or particles with circular trajectories. At these, the inertial coefficients have positive values, but they become periodically variable depending on the displacement, and the mechanical actions have periodic variability depending on the displacement and approximately linear or pathetic depending on the speed.

The most common variations encountered in machines of different types [1] have been brought to fundamental and standard forms [2]. The response of the dynamic model to the fundamental features allows for a series of observations on both behavior and design of the automatic adjustment.

Model

The motion equation of the dynamic disk model, with real values,

$$
\mathrm{J}(\varphi) \cdot \omega \frac{\mathrm{d} \omega}{\mathrm{d} \varphi}+\omega^{2} \frac{1}{2} \frac{\mathrm{dJ}(\varphi)}{\mathrm{d} \varphi}=\mathrm{M}(\varphi, \omega)
$$

preserves its shape for the fundamental characteristics with dimensional values, namely:

$J(x) \cdot y \frac{d y}{d x}+y^{2} \frac{1}{2} \frac{d J(x)}{d x}=k \cdot P(x, y)$

It is noted by $\mathrm{x}$ and $\mathrm{y}$ the dimensional values for displacement and velocity, and also $\mathrm{J}(\mathrm{x})$ by $\mathrm{P}(\mathrm{x}, \mathrm{y})$ the dimensional values of the reduced moment of inertia and the torque torque respectively. 
The value of the global coefficient $\mathrm{k}$ (without dimension) results from the relationship: $\mathrm{k}=\frac{\mathrm{k}_{\mathrm{M}} \cdot \mathrm{k}_{\varphi}}{\mathrm{k}_{\mathrm{I}} \cdot \mathrm{k}_{\omega}^{2}}$

We accepted [2] the moment of inertia and the moment of torque reduced in the forms:

$\mathrm{J}(\mathrm{x})=\mathrm{I}+\mathrm{I}(\mathrm{x})$

$\mathrm{P}(\mathrm{x}, \mathrm{y})=\mathrm{M}(\mathrm{x})+\mathrm{K} \cdot \mathrm{M}(\mathrm{y})$

Typical forms [2] are considered for the inertial characteristic $I(x)$ and mechanical feature $\mathrm{M}(\mathrm{x})$ the shape of the triangular feature $\mathrm{I}(\mathrm{x})=\mathrm{T} \mathrm{M}(\mathrm{x})=\mathrm{T}$ (Figure 1), and for the mechanical characteristic $\mathrm{M}(\mathrm{y})$ is considered to be the Simple Right feature $\mathrm{M}(\mathrm{y})=\mathrm{DS}$ (Figure 2).

The maximum amplitude of the $\mathrm{T}$ characteristic is equal to the unit, but it can be conveniently modified by the coefficients I and $\mathrm{K}$ to correspond to the actual values [2] and the period is two units. It is possible that the actual times of inertia moment and the moment of reduced torque differ between them, the first corresponding to the kinematic cycle, the other corresponding to the dynamic cycle of the machines, and therefore the period of four units is allowed (Figure 1).

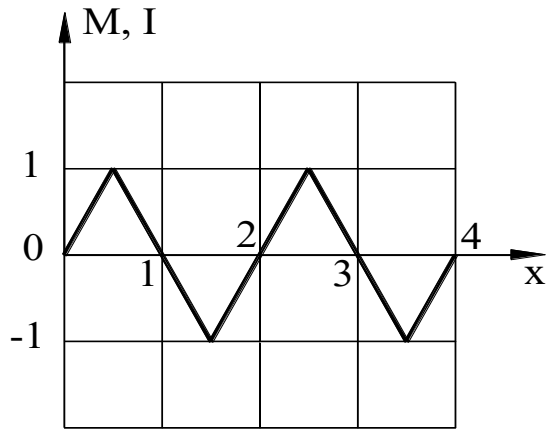

Figure 1. Mechanical feature $M(x)$.

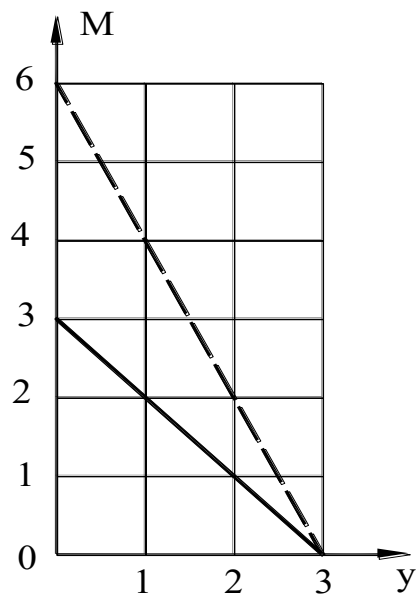

Figure 2. Mechanical characteristic $M(y)$.

The fundamental feature $\mathrm{T}$ has the following forms:

Normal

$$
\mathrm{T}_{\alpha}=(-1)^{\mathrm{n}} \cdot 2(\mathrm{x}-\mathrm{n}) \quad \mathrm{n}=0,1,2 \ldots
$$

out of phase

$$
\mathrm{T}_{\beta}=(-1)^{\mathrm{n}} \cdot 2(\mathrm{n}-\mathrm{x})
$$$$
\mathrm{n}=0,1,2 \ldots
$$

and allows to analyze the dynamic response on five types of charts as follows:

$>$ he base diagram 00 for which $\mathrm{I}(\mathrm{x})=0$ and $\mathrm{M}(\mathrm{x})=0$

$$
\begin{aligned}
& \mathrm{J}(\mathrm{x})=\mathrm{I}=\text { const. } \\
& \mathrm{P}(\mathrm{x}, \mathrm{y})=\mathrm{k} \cdot \mathrm{K} \cdot \mathrm{M}(\mathrm{y})
\end{aligned}
$$

Diagram +11 for which periodic functions $\mathrm{I}(\mathrm{x})$ and $\mathrm{M}(\mathrm{x})$ are in normal form

$$
\mathrm{I}(\mathrm{x})=\mathrm{T}_{\alpha} ; \quad \mathrm{M}(\mathrm{x})=\mathrm{T}_{\alpha}
$$

Diagram \pm 11 for which the periodic function $\mathrm{I}(\mathrm{x})$ corresponds to the feature fundamental $\mathrm{T}$ normal form, and function $\mathrm{M}(\mathrm{x})$ corresponds to the fundamental characteristic $\mathrm{T}$ - phase, ie: $\mathrm{I}(\mathrm{x})=\mathrm{T}_{\alpha}$ $\mathrm{M}(\mathrm{x})=\mathrm{T}_{\beta}$ 
Because $\mathrm{dT} \alpha / \mathrm{dx}=(-1)^{\mathrm{n}} 2$ and $\mathrm{dT} \beta / \mathrm{dx}=(-1)^{\mathrm{n}}(-2)$ the motion equation for the five charts has the following expressions:

$$
\begin{aligned}
& \frac{d y}{d x}=k \frac{K(3-y)}{y \cdot I}=f^{00} \\
& \frac{d y}{d x}=k \frac{(-1)^{n} 2(x-n)+K(3-y)+(-1)^{n} y}{\left[I+(-1)^{n} 2(x-n)\right] \cdot y}=f^{00} \\
& \frac{d y}{d x}=k \frac{(-1)^{n} 2(n-x)+K(3-y)+(-1)^{n} y}{\left[I+(-1)^{n} 2(x-n)\right] \cdot y}=f^{ \pm 11} \\
& \frac{d y}{d x}=k \frac{(-1)^{n} 2(n-x)+K(3-y)-(-1)^{n} y}{\left[I+(-1)^{n} 2(n-x)\right] \cdot y}=f^{-11} \\
& \frac{d y}{d x}=k \frac{(-1)^{n} 2(x-n)+K(3-y)-(-1)^{n} y}{\left[I+(-1)^{n} 2(n-x)\right] \cdot y}=f^{\mu 11}
\end{aligned}
$$

With variation being approximately linear for $\mathrm{I}=10 ; \mathrm{K}=5$, its variation graphs were constructed in relation to the displacement $\mathrm{x}$ as shown in Figures 3 and 4.

While maintaining the same $\mathrm{K} / \mathrm{I}$ ratio at high I-values, the phase trajectory exhibits less concavity on intervals, the variation being approximately linear for $\mathrm{I}=10 ; \mathrm{K}=5$ (Figure 3 ) and with a lower degree of unevenness. Return points are no longer reported for $\mathrm{I}=100 ; \mathrm{K}=50$, identifying it with the dynamic answer for the underlying diagram.
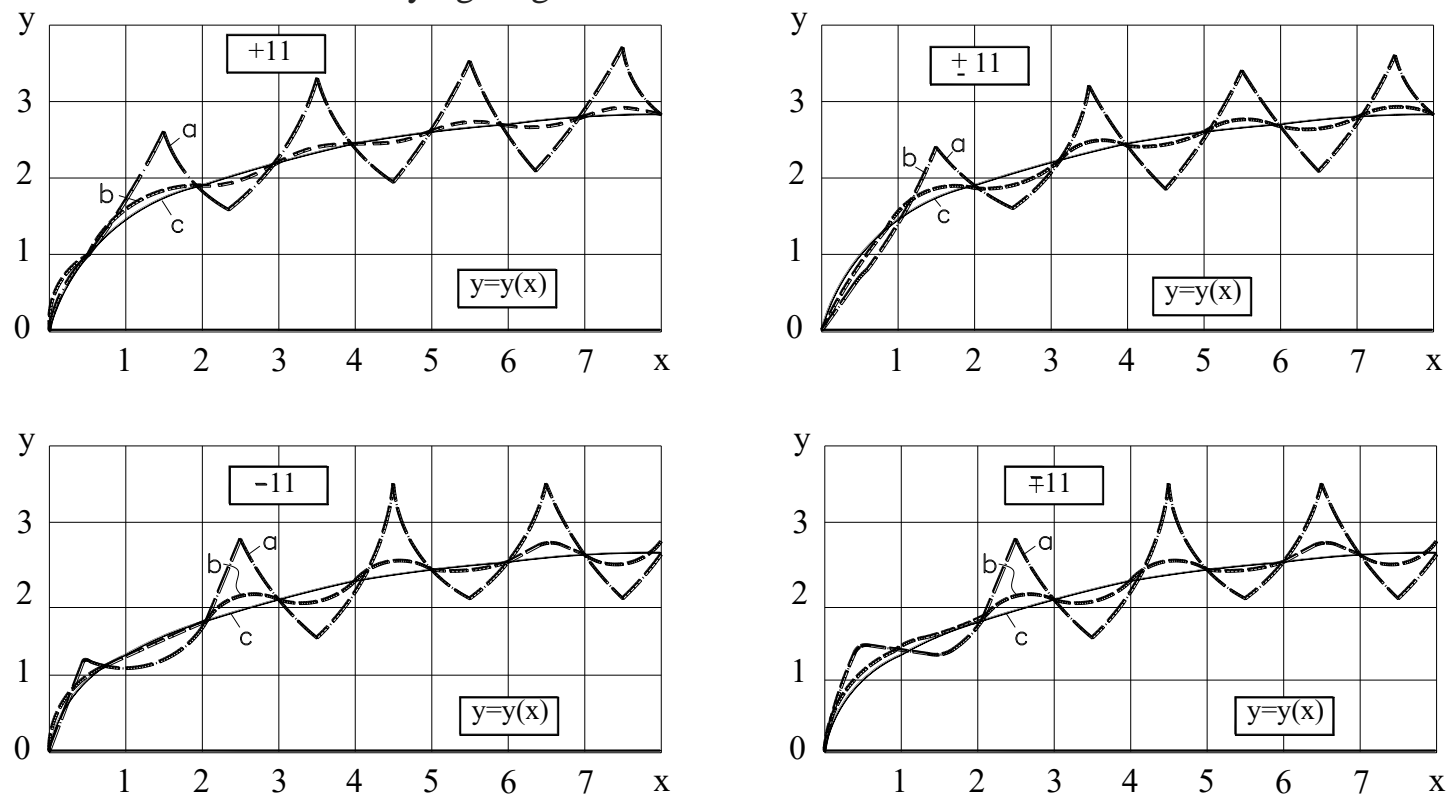

$$
a \rightarrow I=2 ; K=1
$$$$
\mathrm{b}-\mathrm{I}=10 ; \mathrm{K}=5
$$$$
c \rightarrow I=100 ; K=50
$$

Figure 3. Variation graphs were constructed in relation to the displacement $x$ 
High values of the $\mathrm{K}$ constant lead to a reduction in the start-up phase, the phase of the phase beginning even after the first period of the $\mathrm{I}(\mathrm{x})$ and $\mathrm{M}(\mathrm{x})$ to values $\mathrm{I}=10 ; \mathrm{K}=50$ and after $1 / 4$ of the period to values $I=2 ; K=50$ (Figure 4). In this case, the variation of the dynamic response in the mode phase takes place around $\mathrm{y}=3$.
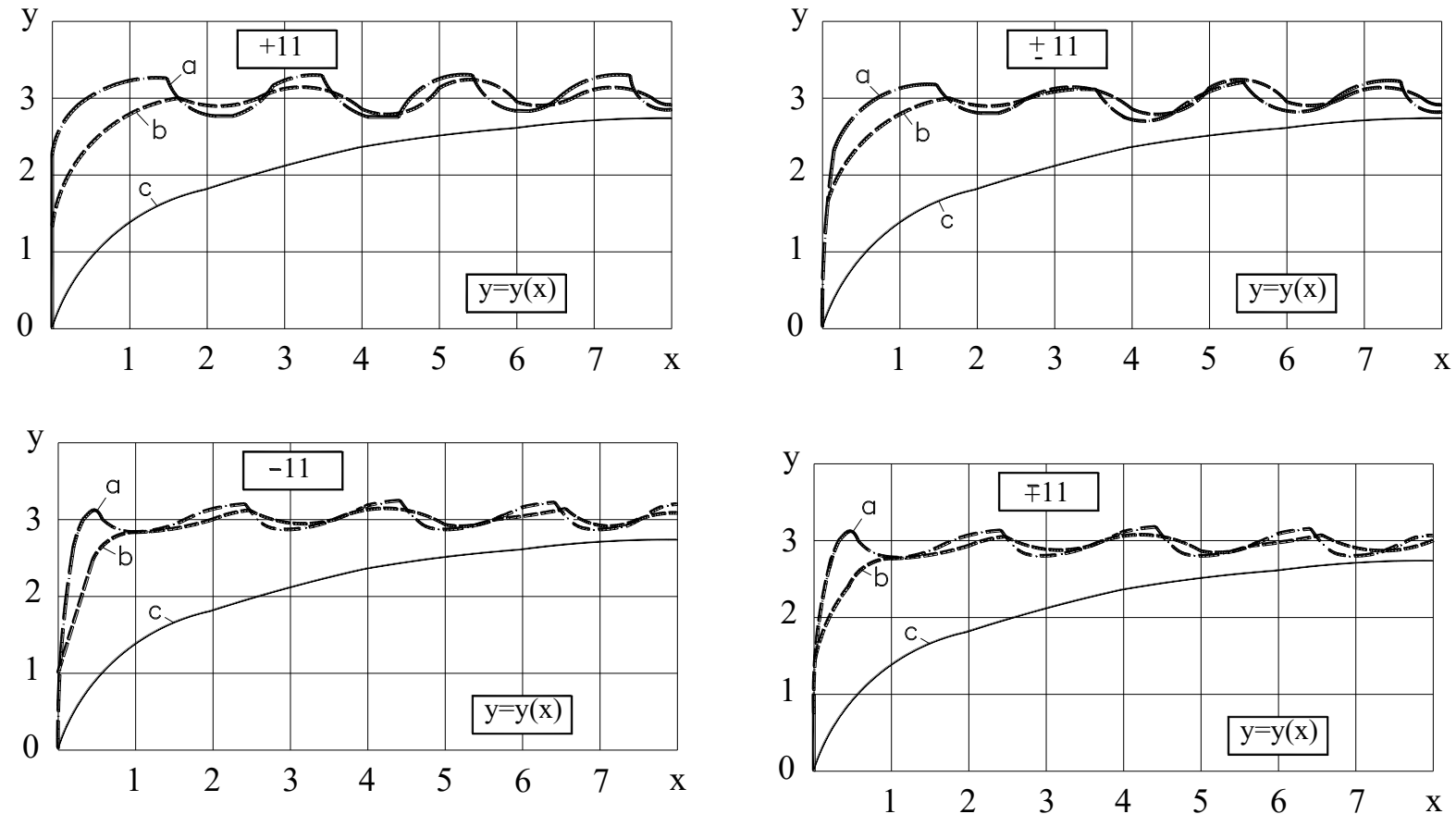

$$
a \rightarrow I=2 ; K=50 \quad b \rightarrow I=10 ; K=50 \quad c \rightarrow I=100 ; K=50
$$

Figure 4. Variation graphs were constructed in relation to the displacement $\mathrm{x}$

\section{Conclusions:}

In order to integrate the motion equation, the Runge-Kutta methods of the 4th order were developed. A computational program was developed in Fortran, which was run on the Felix-256 computer and allows to determine the parameters: speed, energy, moment of inertia.

In the phase of the diagrams, diagrams $+11 ; \pm 11$ are offset against the -11 charts; + and - for the same values of constants I and $\mathrm{K}$.

\section{References}

[1] Pelecudi C H R, Precizia Mecanismelor 1975, Ed. Acad. R.S.R., Bucureşti.

[2] Pelecudi C H R, Deciu E, Grecu B, Răspunsul modelului dynamic al maşinilor cu caracteristici geometrice şi mecanice standard 1977, vol 2, II-nd International Simposion of mechanism, Bucureşti

[3] Pelecudi C H R, Grecu B, Modelul dimanic al mecanismelor cu caracteristicile PP-DS 1981, vol. 1, III-nd International Simposion of mechanism, Bucureşti

[4] Martin Chuaqui, General criteria for curves to be simple, Journal of Mathematical Analysis and Applications, august,vol.464,2018. 